Original Article

\title{
Relationships among foot position, lower limb alignment, and knee adduction moment in patients with degenerative knee osteoarthritis
}

\author{
YuMi Cho, PT, MSc ${ }^{1)}$, YoungJun Ko, PT, MSc1), Wanhee Lee, PT, PhD ${ }^{1 *}$ \\ 1) Department of Physical Therapy, Sahmyook University: 26-21 Gongneung 2-dong, Nowon-gu, Seoul \\ 139-742, Republic of Korea
}

\begin{abstract}
Purpose] The aim of this study was to determine the relationships among the foot progression angle, foot rotation angle, lower limb alignment, and knee adduction moments in patients with degenerative knee osteoarthritis (OA). [Subjects] Forty-eight patients diagnosed with degenerative knee OA (Kellgren-Lawrence grades 2 and 3) were included. [Methods] To assess the lower extremity alignment and weight-bearing ratio, static radiographic measurement was used. Foot progression angle, foot rotation angle, and knee adduction moments were measured by using a three-dimensional motion analysis system. [Results] The results of this study were as follows: the foot progression angle in the early and late stance phase was significantly correlated with the first and second peak knee adduction moments; the weight-bearing ratio was significantly correlated with the first and second peak knee adduction moments; and the tibiofemoral angle was significantly correlated with the first and second peak knee adduction moments. [Conclusion] The results of the present study indicated that as the foot progression angle and the foot lateral rotation angle increased, the knee adduction moment decreased. The weight-bearing ratio and tibiofemoral angle assessment with mechanical axis alignment were correlated with the knee adduction moments. These parameters may be helpful for selecting therapeutic options for patients with degenerative knee OA.

Key words: Knee osteoarthritis, Knee adduction moment, Foot rotation angle
\end{abstract}

(This article was submitted Jun. 24, 2014, and was accepted Aug. 24, 2014)

\section{INTRODUCTION}

Osteoarthritis (OA) is the most prevalent disease associated with significant morbidity, and it is one of the most common causes of functional limitation and dependency. Knee OA is particularly disabling because of symptoms such as pain, stiffness, and muscle weakness ${ }^{1,2)}$. It causes difficulty in climbing stairs, rising from a seated position, and walking, eventually leading to physical disability and decreased quality of life $\mathrm{e}^{3,4)}$.

In many previous studies, associations between the mechanical axis alignment of the lower limb and OA severity were found ${ }^{5-9)}$. Malalignments of the knee joint make individuals more susceptible to developments of knee $\mathrm{OA}^{7)}$, and valgus or varus alignment increase the risk of knee OA occurrence $^{6,10)}$. Varus alignment, in particular, resulted in the largest stresses at the medial compartment of the knee ${ }^{5)}$.

The adduction moment at the knee during gait is the primary determinant of the medial-to-lateral distribution $^{11)}$. Measurement of the knee joint moments provides

*Corresponding author. Wanhee Lee (E-mail: whlee@syu. ac.kr)

C2015 The Society of Physical Therapy Science. Published by IPEC Inc. This is an open-access article distributed under the terms of the Creative Commons Attribution Non-Commercial No Derivatives (by-ncnd) License $<$ http://creativecommons.org/licenses/by-nc-nd/3.0/> . an indication of the actual knee joint loads related with the progression of $\mathrm{OA}^{12)}$. The knee adduction moment is mainly determined by the ground reaction force and its lever arm. The line of action of the ground reaction force is directed to the medial side and the center of the knee during gait, and its lever arm is the perpendicular distance from this force vector to the knee joint center. The knee adduction moment tends to adduct the knee into a varus position, which is significantly correlated with disease severity ${ }^{11)}$.

An altered kinematic pattern of the ankle joint can also influence lower extremity function ${ }^{13-18)}$, and the foot progression angle is related to the knee adduction moment during gait $^{19-22)}$. During the late stance phase in the gait cycle, the ground reaction force passes through the forefoot, and medial to lateral disturbances caused by foot rotation influence knee kinetics ${ }^{23)}$. Thus, patients with knee OA tend to rotate their foot in order to reduce their adduction moments ${ }^{24)}$.

Most previous studies on foot position and knee adduction moment have focused on foot progression ${ }^{19,22)}$. Only a few studies have examined the relationship between the foot rotation angle and knee adduction moment. Therefore, the purpose of this study was to investigate the relationships among the foot progression angle, foot rotation angle, lower limb alignment, and knee adduction moments in patients with degenerative knee OA. 
Table 1. General characteristics of the subjects $(\mathrm{N}=48)$

\begin{tabular}{lcc}
\hline Parameters & \multicolumn{2}{c}{ Values } \\
\hline Kellgren-Lawrence & 2nd grade & $(21)$ \\
radiographic criteria (n) & 3rd grade & $(27)$ \\
VAS (scores) & $6.5 \pm 1.6$ \\
Age (years) & $70.5 \pm 4.7$ \\
Height $(\mathrm{cm})$ & $154.2 \pm 4.9$ \\
Weight $(\mathrm{kg})$ & $64.7 \pm 8.4$ \\
Foot length $(\mathrm{cm})$ & $22.8 \pm 0.9$ \\
Foot breadth $(\mathrm{cm})$ & $10.2 \pm 0.7$ \\
Cadence $(\mathrm{steps} / \mathrm{min})$ & $121.8 \pm 9.1$ \\
Gait speed $(\mathrm{cm} / \mathrm{s})$ & $118.9 \pm 10.5$ \\
Step length $(\mathrm{cm})$ & $117.5 \pm 11.7$ \\
Stride length $(\mathrm{cm})$ & $8.9 \pm 1.8$ \\
\hline Values are means \pm SD. VAS: Visual Analogue \\
Scale
\end{tabular}

\section{SUBJECTS AND METHODS}

We included 48 female patients aged 65 years and older who were diagnosed by radiography with degenerative knee OA (Kellgren-Lawrence grades 2 and 3). We excluded patients who received more than 7 points in a physical therapy evaluation, which included an assessment of sensation, circulation, range of motion, muscle strength of the lower limbs, and problems concerning the feet and balance ${ }^{25)}$. Additional exclusion criteria were as follows: cardiovascular disease, diabetes, peripheral nervous disease, history of lower extremity surgery, difficulties with visual or auditory function, and cognitive disorder (Korean MiniMental State Examination score $\leq 24$ ). The purpose of the study was explained to the participants, and informed consent was obtained. The study protocol was approved by the institutional review board of Sahmyook University, Seoul, Republic of Korea.

To assess the lower extremity alignment and weightbearing ratio, a static radiographic measurement system (Shimadzu $500 \mathrm{~mA}$ and $35.56 \times 91.44 \mathrm{~cm}$ cassette; Shimadzu Seisakusho, Ltd., Kyoto, Japan) was used. To minimize errors during knee angle assessment, the focus-film distance was set at $183 \mathrm{~cm}$. The examiner conducted anterior-posterior radiography while subjects stood with their knees straight and their big toe and heel aligned with a marked line. The examiner measured the knee angle radiographically using a goniometer and ruler.

The foot progression angle, foot rotation angle, and knee adduction moments were measured by using a threedimensional motion analysis system (Orthostat 6.29; Motion Analysis, Inc., Santa Rosa, CA, USA) composed of two force plates (piezoelectric force plate, $600 \times 900 \mathrm{~mm}$; Kistler Corp., Winterthur, Switzerland), six infrared cameras, and $25 \mathrm{~mm}$ reflective markers. The reflective markers were attached to the right and left of the center of the sacrum, anterior superior iliac spine, middle point between the greater trochanter and lateral femoral condyle, lateral femoral condyle, middle point between the femoral condyle and lateral
Table 2. Foot position, knee adduction moment, and lower limb alignment of the subjects $(\mathrm{N}=48)$

\begin{tabular}{lc}
\hline \multicolumn{1}{c}{ Parameters } & \multicolumn{1}{c}{ Values } \\
\hline Foot progression angle $\left(^{\circ}\right)$ & \\
Early stance phase & $10.95 \pm 5.81$ \\
Late stance phase & \\
Foot rotation angle $\left(^{\circ}\right)$ & $1.14 \pm 6.13$ \\
Early stance phase & $0.41 \pm 1.07$ \\
Late stance phase & \\
Knee adduction moment $(\mathrm{Nm} / \mathrm{kg})$ & $0.55 \pm 0.13$ \\
1st peak value & $0.47 \pm 0.16$ \\
2nd peak value & $32.0 \pm 12.2$ \\
Weight-bearing ratio $(\%)$ & $3.60 \pm 2.22$ \\
Tibiofemoral angle $\left(^{\circ}\right)$ & \\
Femoral valgus angle $\left(^{\circ}\right)$ & $5.19 \pm 1.49$ \\
Medial & $4.16 \pm 1.90$ \\
Lateral & $8.79 \pm 5.46$ \\
Patellofemoral Q angle $\left(^{\circ}\right)$ & $9.23 \pm 5.40$ \\
Patellotibial Q angle $\left({ }^{\circ}\right)$ &
\end{tabular}

Values are means \pm SD

malleolus, lateral malleolus, calcaneus, and 2nd metatarsal bone.

After a warm-up walk, the assessment was conducted five times, and the subjects were asked to walk as usual and had a 2 min rest during the intervals between the assessments.

The foot progression angle and foot rotation angle were measured at the point of the first peak knee adduction moment in the early stance phase and during the second peak knee adduction moment in the late stance phase. Additionally, we measured lower limb alignment and the first and second peak knee adduction moments.

The SPSS version 12.0 software (SPSS, Inc., Chicago, IL, USA) was used to perform statistical analyses. Descriptive statistics were used for general features. To determine the relationships among foot position, lower limb alignment, and knee adduction moments in the subjects, we used Pearson's correlation coefficient. The level of statistical significance was $\mathrm{p}<0.05$.

\section{RESULTS}

The general characteristics and gait analysis results of the subjects are described in Table 1. The foot position, knee adduction moments, and lower limb alignment of the subjects are summarized in Table 2.

In the early and late stance phases, the foot progression angle was significantly correlated with the first and second peak values of the knee adduction moments $(p<0.05)$ (Table $3)$. The weight-bearing ratio was significantly correlated with the first and second peak knee adduction moments. The tibiofemoral angle was significantly correlated with the first and second peak knee adduction moments $(\mathrm{p}<0.05)$ (Table 4). 
Table 3. Relationship between foot position and knee adduction moment $(\mathrm{N}=48)$

\begin{tabular}{ccc}
\hline \multirow{2}{*}{ Foot position } & \multicolumn{2}{c}{ Knee adduction moment } \\
\cline { 2 - 3 } & $\begin{array}{c}\text { 1st peak } \\
\text { value }\end{array}$ & $\begin{array}{c}\text { 2nd peak } \\
\text { value }\end{array}$ \\
\hline Foot progression angle $\left(^{\circ}\right)$ & & \\
Early stance phase & $-0.30^{\mathrm{a} *}$ & $-0.45^{*}$ \\
Late stance phase & $-0.33^{*}$ & $-0.48^{*}$ \\
Foot rotation angle $\left(^{\circ}\right)$ & & \\
Early stance phase & 0.08 & $0.31^{*}$ \\
Late stance phase & 0.14 & $0.38^{*}$ \\
\hline
\end{tabular}

aPearson's correlation coefficient. * $\mathrm{p}<0.05$

\section{DISCUSSION}

The results of the present study indicated that as the foot progression angle and foot lateral rotation angle increased, the knee adduction moment decreased. In addition, the weight-bearing ratio and tibiofemoral angle assessment with mechanical axis alignment were correlated with the knee adduction moments. We found that a higher foot progression angle was correlated with a reduction in knee adduction moments. A study by Lin et al. demonstrated a reduced peak knee adduction moment when out-toeing during normal walking ${ }^{22)}$. Additionally, a study by Teichtahl et al. showed that subjects who walked with their feet externally rotated reduced their knee adduction moment during the late stance phase $^{23)}$. Guo et al. suggested that walking with a toe-out strategy may be beneficial for persons in the early stages of medial knee OA, because the toe-out foot position can transfer ground reaction force to the outside of the foot, resulting in a reduction in knee adduction moment ${ }^{20)}$.

Our results showed that the foot rotation angle was higher in the second knee adduction moment. Similarly, Teichtahl et al. described that the foot rotation position was more related to the late stance phase than the early stance phase because of the ground reaction forces distributed to the forward, inside, and outside parts of the foot ${ }^{23}$.

Anatomical lower limb alignment assessment of the knee measured on standard knee radiographs is widely used to investigate the relationship with the knee adduction moment $^{5,10,26)}$ and to detect the progression of degenerative knee $\mathrm{OA}^{23,27-30)}$. The anatomical tibiofemoral angle of the knee obtained using a short cassette $(35.56 \times 43.18 \mathrm{~cm})$ is more widely used because of its economical and practical benefits. However, a limitation of this measurement is its wide variation due to exclusion of the hip and ankle joints ${ }^{28)}$. Thus, we used a measurement method that assessed the mechanical tibiofemoral angle and the weight-bearing ratio using the hip, knee, and ankle angles with full-limb radiographs using a long cassette $(35.56 \times 91.44 \mathrm{~cm})$.

The weight-bearing ratio is calculated by measuring the distance from the medial edge of the proximal tibia to the point where the weight-bearing line intersects the proximal tibia and then dividing the measurement by the entire width of the proximal tibia; the percentage is calculated by multiplying this ratio by $100 \%$. By definition, a weight-bearing
Table 4. Relationship between lower limb alignment and knee adduction moment $(\mathrm{N}=48)$

\begin{tabular}{lcc}
\hline \multirow{2}{*}{ Lower limb alignment } & \multicolumn{2}{c}{ Knee adduction moment } \\
\cline { 2 - 3 } & $\begin{array}{c}\text { 1st peak } \\
\text { value }\end{array}$ & $\begin{array}{c}\text { 2nd peak } \\
\text { value }\end{array}$ \\
\hline Weight-bearing ratio (\%) & $-0.58^{\text {a* }}$ & $-0.62^{*}$ \\
Tibiofemoral angle $\left({ }^{\circ}\right)$ & $0.57^{*}$ & $0.59^{*}$ \\
Femoral valgus angle $\left({ }^{\circ}\right)$ & & \\
Medial & 0.39 & 0.27 \\
Lateral & 0.08 & 0.23 \\
Patellofemoral Q angle $\left({ }^{\circ}\right)$ & -0.06 & 0.22 \\
Patellotibial Q angle $\left({ }^{\circ}\right)$ & -0.01 & 0.30 \\
\hline aPearson's correlation coefficient. ${ }^{*} \mathrm{p}<0.05$ &
\end{tabular}

line of $<50 \%$ indicates varus alignment of the lower extremity, and a line $>50 \%$ indicates valgus alignment ${ }^{19}$. In our results, the weight-bearing ratio was significantly correlated with the first knee adduction moment and the second knee adduction moment, meaning that as the knee adduction moment in the early and late stance phase increased, the inside of the knee joint loading increased.

In the present study, the tibiofemoral angle of the subjects was $3.60^{\circ} \pm 2.22^{\circ}$, which was greater than that of a normal person $\left(1.2-2.2^{\circ}\right)^{30)}$, because the subjects had knee OA with varus alignment. Regarding the relationship between the tibiofemoral angle and the knee adduction moment, the first and second knee adduction moments were significantly correlated with the valgus alignment angle.

The femoral valgus angle was $5.19^{\circ}$ at the time of measurement of the medial tibiofemoral angle and was $4.16^{\circ}$ at the time of measurement of the lateral tibiofemoral angle. These values were less than that of the normal group $\left(6^{\circ}\right)^{31)}$, because the subjects with knee OA had varus alignment. Therefore, there was no relationship between the femoral valgus angle and the knee adduction moment in our subjects. The normal anatomical $Q$ angle is $15 \pm 3^{\circ 30}$ ), but in our subjects, the patellofemoral $\mathrm{Q}$ angle was $8.7^{\circ}$, and the patellotibial Q angle was $9.2^{\circ}$, both of which were less than the normal range due to the varus deformity of the knee joints. Additionally, there was no significant relationship between the $\mathrm{Q}$ angle and the knee adduction moment.

In conclusion, we found that as the foot progression angle and foot lateral rotation angle increased, the knee adduction moment decreased. The weight-bearing ratio and tibiofemoral angle assessment with mechanical axis alignment were correlated with the knee adduction moments. However, the femoral valgus angle and anatomical Q angle may not be relevant to the knee adduction moment. Therefore, the mechanical tibiofemoral angle is more appropriate for assessing patients with knee OA than anatomical lower limb assessment. These findings may be helpful for selecting therapeutic options for patients with degenerative knee OA.

\section{REFERENCES}

1) McAlindon TE, Cooper C, Kirwan JR, et al.: Knee pain and disability in the community. Br J Rheumatol, 1992, 31: 189-192. [Medline] [CrossRef] 
2) O'Reilly SC, Jones A, Muir KR, et al.: Quadriceps weakness in knee osteoarthritis: the effect on pain and disability. Ann Rheum Dis, 1998, 57 588-594. [Medline] [CrossRef]

3) Ayis S, Dieppe P: The natural history of disability and its determinants in adults with lower limb musculoskeletal pain. J Rheumatol, 2009, 36 583-591. [Medline] [CrossRef]

4) Igawa T, Katsuhira J: Biomechanical analysis of stair descent in patients with knee osteoarthritis. J Phys Ther Sci, 2014, 26: 629-631. [Medline] [CrossRef]

5) Mündermann A, Dyrby CO, Andriacchi TP: A comparison of measuring mechanical axis alignment using three-dimensional position capture with skin markers and radiographic measurements in patients with bilateral medial compartment knee osteoarthritis. Knee, 2008, 15: 480-485. [Medline] [CrossRef]

6) Sheehy L, Felson D, Zhang Y, et al.: Does measurement of the anatomic axis consistently predict hip-knee-ankle angle (HKA) for knee alignmen studies in osteoarthritis? Analysis of long limb radiographs from the multicenter osteoarthritis (MOST) study. Osteoarthritis Cartilage, 2011, 19: 58-64. [Medline] [CrossRef]

7) Yang NH, Nayeb-Hashemi H, Canavan PK, et al.: Effect of frontal plane tibiofemoral angle on the stress and strain at the knee cartilage during the stance phase of gait. J Orthop Res, 2010, 28: 1539-1547. [Medline] [CrossRef]

8) Son H, Kim K: A kinematic analysis of patients with knee osteoarthriti during gait on level ground, ramps and stairs. J Phys Ther Sci, 2013, 25: 277-280. [CrossRef]

9) Emrani A, Bagheri H, Hadian MR, et al.: Isokinetic strength and functional status in knee osteoarthritis. J Phys Ther Sci, 2006, 18: 107-114. [CrossRef]

10) Moyer RF, Birmingham TB, Chesworth BM, et al.: Alignment, body mass and their interaction on dynamic knee joint load in patients with knee osteoarthritis. Osteoarthritis Cartilage, 2010, 18: 888-893. [Medline] [CrossRef]

11) Sharma L, Hurwitz DE, Thonar EJ, et al.: Knee adduction moment, serum hyaluronan level, and disease severity in medial tibiofemoral osteoarthritis. Arthritis Rheum, 1998, 41: 1233-1240. [Medline] [CrossRef]

12) Baliunas AJ, Hurwitz DE, Ryals AB, et al.: Increased knee joint loads during walking are present in subjects with knee osteoarthritis. Osteoarthritis Cartilage, 2002, 10: 573-579. [Medline] [CrossRef]

13) Gribble PA, Robinson RH: Alterations in knee kinematics and dynamic stability associated with chronic ankle instability. J Athl Train, 2009, 44 350-355. [Medline] [CrossRef]

14) Higginson JS, Zajac FE, Neptune RR, et al.: Effect of equinus foot placement and intrinsic muscle response on knee extension during stance. Gait Posture, 2006, 23: 32-36. [Medline] [CrossRef]

15) McPoil TG, Warren M, Vicenzino B, et al.: Variations in foot posture and mobility between individuals with patellofemoral pain and those in a control group. J Am Podiatr Med Assoc, 2011, 101: 289-296. [Medline] [CrossRef]

16) Stergiou N, Bates BT, Kurz MJ: Subtalar and knee joint interaction during running at various stride lengths. J Sports Med Phys Fitness, 2003, 43:
319-326. [Medline]

17) Wesdock KA, Edge AM: Effects of wedged shoes and ankle-foot orthoses on standing balance and knee extension in children with cerebral palsy who crouch. Pediatr Phys Ther, 2003, 15: 221-231. [Medline] [CrossRef]

18) Lee D, Lee S, Park J, et al.: The effect of fixed ankle and knee joints on postural stability and muscle activity. J Phys Ther Sci, 2013, 25: 33-36. [CrossRef]

19) Andrews M, Noyes FR, Hewett TE, et al.: Lower limb alignment and foot angle are related to stance phase knee adduction in normal subjects: a critical analysis of the reliability of gait analysis data. J Orthop Res, 1996, 14: 289-295. [Medline] [CrossRef]

20) Guo M, Axe MJ, Manal K: The influence of foot progression angle on the knee adduction moment during walking and stair climbing in pain free individuals with knee osteoarthritis. Gait Posture, 2007, 26: 436-441. [Medline] [CrossRef]

21) Hurwitz DE, Ryals AB, Case JP, et al.: The knee adduction moment during gait in subjects with knee osteoarthritis is more closely correlated with static alignment than radiographic disease severity, toe out angle and pain. J Orthop Res, 2002, 20: 101-107. [Medline] [CrossRef]

22) Lin CJ, Lai KA, Chou YL, et al.: The effect of changing the foot progression angle on the knee adduction moment in normal teenagers. Gait Posture, 2001, 14: 85-91. [Medline] [CrossRef]

23) Teichtahl AJ, Morris ME, Wluka AE, et al.: Foot rotation-a potential target to modify the knee adduction moment. J Sci Med Sport, 2006, 9: 67-71. [Medline] [CrossRef]

24) Lynn SK, Kajaks T, Costigan PA: The effect of internal and external foot rotation on the adduction moment and lateral-medial shear force at the knee during gait. J Sci Med Sport, 2008, 11: 444-451. [Medline] [CrossRef]

25) Speechley M, Tinetti M: Falls and injuries in frail and vigorous community elderly persons. J Am Geriatr Soc, 1991, 39: 46-52. [Medline]

26) Maly MR, Culham EG, Costigan PA: Static and dynamic biomechanics of foot orthoses in people with medial compartment knee osteoarthritis. Clin Biomech (Bristol, Avon), 2002, 17: 603-610. [Medline] [CrossRef]

27) Botha-Scheepers $S$, Dougados M, Ravaud P, et al.: Effect of medial tibial plateau alignment on serial radiographs on the capacity to predict progression of knee osteoarthritis. Osteoarthritis Cartilage, 2008, 16: 272-276. [Medline] [CrossRef]

28) Chang CB, Choi JY, Koh IJ, et al.: What should be considered in using standard knee radiographs to estimate mechanical alignment of the knee? Osteoarthritis Cartilage, 2010, 18: 530-538. [Medline] [CrossRef]

29) Cooke D, Scudamore A, Li J, et al.: Axial lower-limb alignment: comparison of knee geometry in normal volunteers and osteoarthritis patients. Osteoarthritis Cartilage, 1997, 5: 39-47. [Medline] [CrossRef]

30) Hsu RW, Himeno S, Coventry MB, et al.: Normal axial alignment of the lower extremity and load-bearing distribution at the knee. Clin Orthop Relat Res, 1990, (255): 215-227. [Medline]

31) Moreland JR, Bassett LW, Hanker GJ: Radiographic analysis of the axial alignment of the lower extremity. J Bone Joint Surg Am, 1987, 69: 745-749. [Medline] 